\title{
Meta-Analysis in Using Satellite Precipitation Products for Drought Monitoring: Lessons Learnt and Way Forward
}

\author{
Gilbert Hinge ${ }^{1}$, Mohamed M. Mohamed ${ }^{1,2} \mathbb{D}$, Di Long ${ }^{3}$ and Mohamed A. Hamouda ${ }^{1,2, *(D)}$ \\ 1 Department of Civil and Environmental Engineering, United Arab Emirates University, \\ Al Ain P.O. Box 15551, United Arab Emirates; ghinge@uaeu.ac.ae (G.H.); m.mohamed@uaeu.ac.ae (M.M.M.) \\ 2 National Water and Energy Center, United Arab Emirates University, \\ Al Ain P.O. Box 15551, United Arab Emirates \\ 3 State Key Laboratory of Hydroscience and Engineering, Department of Hydraulic Engineering, \\ Tsinghua University, Beijing 100084, China; dlong@tsinghua.edu.cn \\ * Correspondence: m.hamouda@uaeu.ac.ae
}

Citation: Hinge, G.; Mohamed, M.M.; Long, D.; Hamouda, M.A. Meta-Analysis in Using Satellite Precipitation Products for Drought Monitoring: Lessons Learnt and Way Forward. Remote Sens. 2021, 13, 4353. https://doi.org/10.3390/rs13214353

Academic Editor: Won-Ho Nam

Received: 26 September 2021

Accepted: 26 October 2021

Published: 29 October 2021

Publisher's Note: MDPI stays neutral with regard to jurisdictional claims in published maps and institutional affiliations.

Copyright: (c) 2021 by the authors. Licensee MDPI, Basel, Switzerland. This article is an open access article distributed under the terms and conditions of the Creative Commons Attribution (CC BY) license (https:// creativecommons.org/licenses/by/ $4.0 /)$.

\begin{abstract}
In recent years, satellite precipitation products (SPPs) have emerged as an essential source of data and information. This work intends to summarize lessons learnt on using SPPs for drought monitoring and to propose ways forward in this field of research. A thorough literature review was conducted to review three aspects: effects of climate type, data record length, and time scale on SPPs performance. The conducted meta-analysis showed that the performance of SPPs for drought monitoring largely depends upon the climate type of the location and length of the data record. SPPs drought monitoring performance was shown to be higher in temperate and tropical climates than in dry and continental ones. SPPs were found to perform better with an increase in data record length. From a general standpoint, SPPs offer great potential for drought monitoring, but the performance of SPPs needs to be improved for operational purposes. The present study discusses blending SPPs with in situ data and other lessons learned, as well as future directions of using SPPs for drought applications.
\end{abstract}

Keywords: drought; Koppen climate; drought monitoring; satellite precipitation products

\section{Introduction}

Precipitation is one of the major components of the Earth's hydrological cycle [1]. In recent years, satellite precipitation products (SPPs) have emerged, making SPPs an essential data source for climatological and hydrological studies [2,3]. SPPs are typically retrieved from passive microwave, satellite-based infrared, and space-borne precipitation radar [4]. There are now many SPPs available, such as Climate Prediction Center MORPHing method (CMORPH) [5], Climate Hazards Group infrared precipitation with station data (CHIRPS) [6], integrated multi-satellite retrievals for GPM (IMERG) [7], precipitation estimation from remotely sensed information using artificial neural networks-climate data record (PERSIANN-CDR) [8], tropical rainfall measuring mission (TRMM) [9] and many others. SPPs have proven to provide data at a high spatial and temporal scale [10]. Moreover, they are capable of producing precipitation data even in inaccessible areas [11-13].

Drought monitoring, defined as tracking the frequency, duration, severity, and whereabouts of drought, is vital for water resources planning and management [14]. Drought monitoring information can help reduce the risk and impact of drought if conveyed to the decision-makers in a timely and correct format $[15,16]$. In recent years, drought events have become more frequent and severe due to increased water demands and climate change [17]. One of the consequences of climate change is an increase in the frequency and occurrence of extreme events $[18,19]$. Among these extreme events, droughts have the most prolonged and severe effects and are one of the least predictable [20]. In recent years, several drought events have impacted tropical, temperate, and dry regions worldwide [21,22]. In addition, 
numerous studies have indicated that precipitation is the precursor of drought onset and persistence $[15,23,24]$. Thus, accurate and timely detection and monitoring of drought are the need of the hour. SPPs can offer a new perspective for drought monitoring. With their high spatial resolution (up to $0.04^{\circ}$ ), high temporal resolution (up to hourly), and comprehensive range coverage (up to $50^{\circ} \mathrm{NS}$ ), SPPs have become one of the potential ideal sources for drought monitoring.

In the last few years, the accuracy of SPPs for drought monitoring has been tested across the globe. Until now, two long-term SPPs, CHIRP (having a data record from 1981) and PERSIANN-CDR (having a data record from 1981), are the most popular SPPs used in drought monitoring due to their long-term data record. These two SPPs (CHIRPS and PERSIANN-CDR) have been developed by combining the long-term historical in situ observations with infrared information [25]. Multiple studies have proved that PERSIANNCDR and CHIRPS performed well across the globe [12,26,27]. In addition, short-term SPPs (having data record less than 30 years), including TRMM, CMORPH, and IMERG, have also been tested and proved to have the potential for drought monitoring [28-30]. However, these past studies have indicated that the performance of SPPs depends upon the climate type, topography, and other factors. Therefore, it is essential to assess the performance of various SPPs to guide future applications of SPPs in drought monitoring.

It is essential to explore the utility of SPPs for effective drought monitoring. Many studies have limited the investigation of the performance of various SPPs to their comparison to ground observations. This leaves a knowledge gap with regard to evaluating and comparing the performance of different SPPs in drought monitoring, particularly the influence of climate conditions, time scale, and record length on such performance. In this article, an evaluation of the application of various SPPs for drought monitoring is conducted. A thorough literature review was conducted to seek answers to the following research questions: Q1. How does the performance of drought monitoring using SPPs vary when applied in different climatic zones? Q2. What is the effect of the length of data records on the effectiveness of SPPs for drought monitoring? Q3. How is the performance of drought monitoring using SPPs vary when applied at different time scales? In addition, the review of the literature helped outline the lessons learned and the way forward of using SPPs for drought monitoring.

\section{Drought Monitoring: The State of the Art}

The World Meteorological Organization (WMO) and the global water partnership have named three primary methods for monitoring drought to guide early warming assessment [31]. These methods can rely on (a) a single indicator or index; (b) composite indicators; or (c) multiple indicators or indices [32]. The selection of appropriate drought indicators that are widely acknowledged and suitable for a particular location is the most crucial step in drought monitoring. The standardized precipitation index (SPI) developed by McKee et al. [33] was recommend by WMO as the primary index with which to track the meteorological drought. However, no consensus has been made on the standard index for other types of drought [34]. A general concept in using a drought index to monitor various kinds of droughts is shown in Figure 1. There is no 'one size fits all' index applied for all types of droughts [35]. Depending upon the data availability and type of use, different indicators can be developed to define different drought types, as shown in Figure 1. In recent times, researchers have tried to develop a hybrid indicator, for example, a multivariate standardized index, vegetation drought response index (VegDRI) [36], evaporative stress index (ESI) [37], and process-based accumulated drought index (PADI) [38] to merge multiple indicators. The idea is to use the strength of various inputs and yet maintain a single index for policy and decision-makers [39]. 


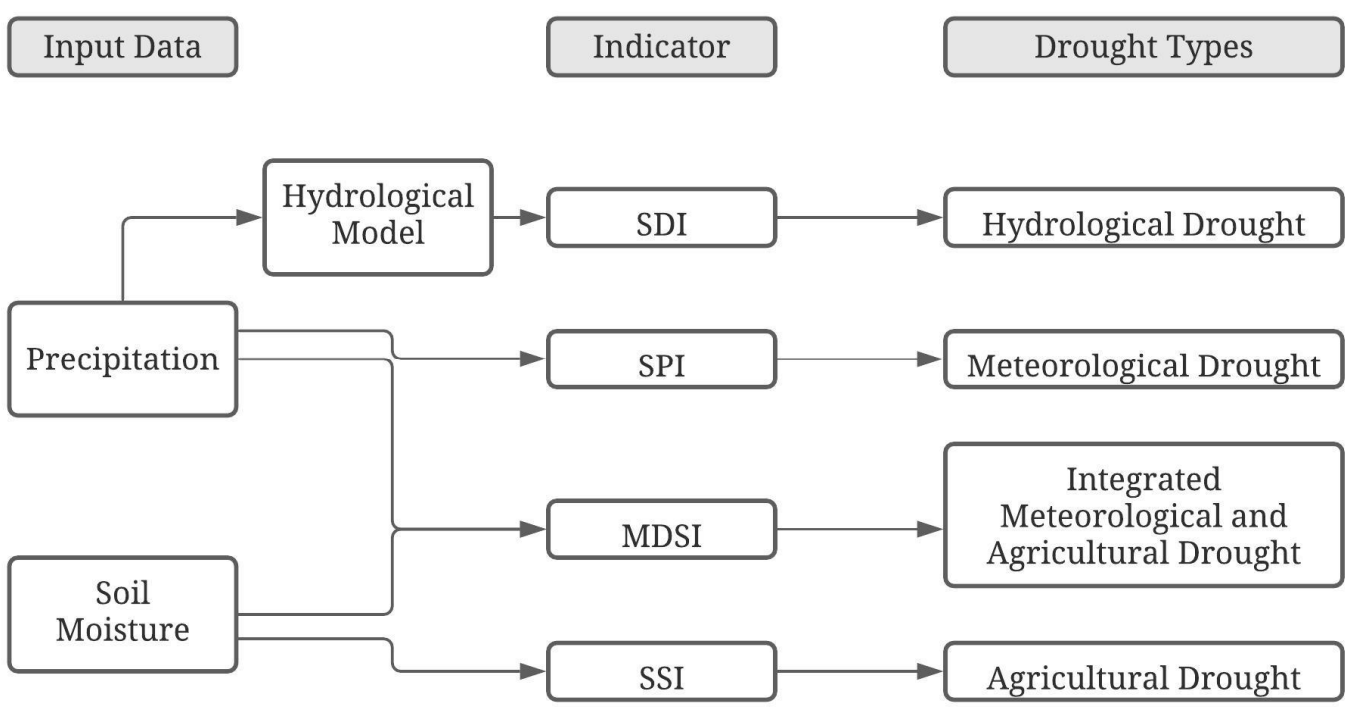

Figure 1. Schematic view of the general concept of using drought indices to monitor various types of droughts (SPI: standardized precipitation index, SDI: streamflow drought index, SSI: standardized soil moisture index; MDSI: multivariate drought standardized index).

This article focused only on meteorological drought, which depends on the precipitation data (as shown in Figure 1) to single out the effect of SPPs. Other types of droughts that rely on different sets of data and thus obscure the impact of SPPs are not considered for the present study. SPI, an index for defining meteorological drought, has various advantages over other indices [33], because (a) it requires only rainfall data, which makes it suitable for regions that have scarce hydro-meteorological datasets, and (b) it can be computed for different timescales such as $1,3,6,12,24$, or 48 months, which make it possible to study different types of droughts. One of the shortcomings of SPI is that it deals only with the precipitation deficit and does not consider evapotranspiration of this issue [40]. Table 1 shows the drought classification using SPI. A drought event is characterized by values of SPI $<-1$ [33].

Table 1. Classification of droughts based on the SPI value [33].

\begin{tabular}{cc}
\hline SPI Value & Classification \\
\hline$>2$ & Extremely wet \\
1.50 to 1.99 & Very Wet \\
1.00 to 1.49 & Moderately wet \\
-0.99 to 0.99 & Near Normal \\
-1.0 to -1.49 & Moderately dry \\
-1.5 to -1.99 & Severely dry \\
$<-2.0$ & Extremely dry \\
\hline
\end{tabular}

\section{Review Methodology}

\subsection{Methodology for Selection and Screening of Articles}

In order to find relevant literature on the use of SPPs for drought monitoring, the search followed a structured method for screening and selecting manuscripts (Figure 2). Below is an outline of the process: 


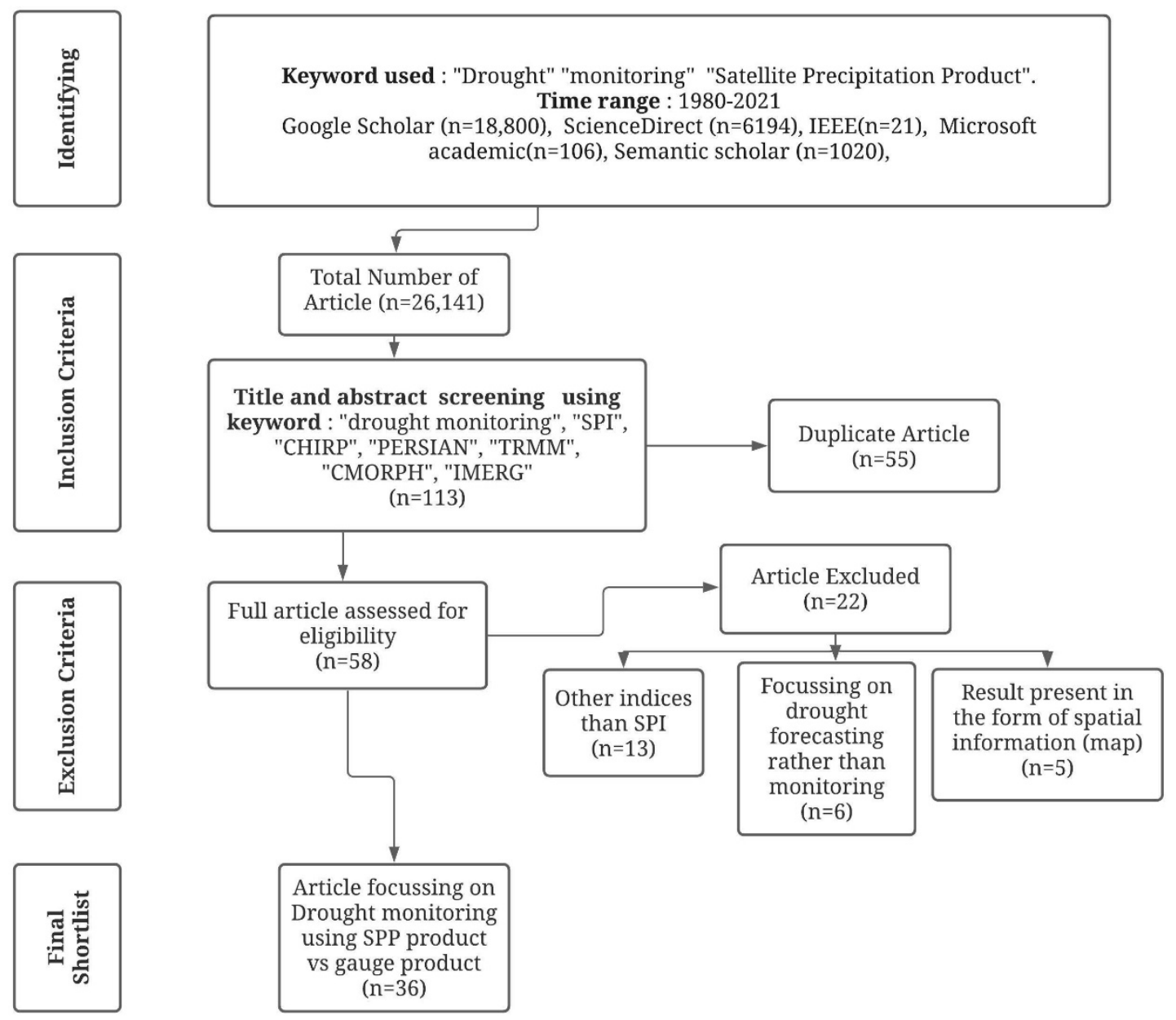

Figure 2. Flowchart of the methodology for selection and screening of articles ( $\mathrm{n}=$ number of articles).

Step I Identifying: A preliminary search was carried out to identify relevant articles. The present study starts by performing a simple search in Google Scholar, ScienceDirect, IEEE, Microsoft academic, and Semantic scholar, using the search keyword "Drought" "Satellite Precipitation product" "monitoring" and limiting the year of publication to 19802021. Step II Initial Screening: For the first level of screening, the title and abstract of the papers were independently screened. Only papers with title and abstract dealing with drought monitoring using SPI and one of the following SPPs: "CHIRP, PERSIANN CDR, CMORPH, TRMM, and IMERG," were considered for the next step. Due to the limited resource, publications in languages other than English were excluded. All publications with the same title and authors' names and published in the same journal are removed. Abstract only papers were also excluded. Step III Relevance Screening: The present study considers the standardized precipitation index as an index to characterized drought. Thus, in cases where other indices were used in the study for consistencies of comparison, these studies were excluded. If the data were represented in graphical format, the authors checked for supplementary files or contacted the corresponding authors. Where there was no supplementary materials or the corresponding authors did not reply, the papers were excluded from the analysis. Step IV Final Shortlist: In the final steps, essential information such as the type of SPPs used, location of the study, number of years of the data record, climate type, etc., were recorded. Studies that were conducted on a larger geographical area (e.g., covering different climatic zones) were counted in each area, making the total number of studies surpass the actual number of the article reviewed (36 articles). Finally, a database was created using the extracted data from these selected publications. The database included essential basic metrics to allow for an overall initial evaluation of the performance of SPPs in drought monitoring. 


\subsection{Performance Analysis of SPPs in Drought Monitoring}

\subsubsection{Effect of Climatic Zones on the Performance of SPPs in Drought Monitoring}

The present study used the Koppen climate classification [41] to evaluate the effect of the climatic zone on the performance of SPPs in drought monitoring. Koppen climate classification consists of five major groups and multiple subtypes within each main group. This study focuses only on the main five major groups to evaluate SPP's performance. The Koppen climate type of the study location is directly extracted from the paper if mentioned; otherwise, the latitude and longitude of the study location are overlayed on the shapefile of the World Koppen climate map in ArcGIS to obtain the climate class type of the study location. Figure 3 shows the flowchart of the methodology used to evaluate the suitability of SPPs in monitoring meteorological drought across various climate types. SPI 3 and SPI 6 , the two most reported timescales in the selected literature for this study, were considered for the analysis. The Pearson correlation coefficient (PCC) and the root mean square error (RMSE) were used as metrics to evaluate the performance of SPPs. These metrics are expressed as follows:

$$
\begin{gathered}
\text { PCC }=\frac{\sum\left(X_{i}-\bar{X}\right)\left(Y_{i}-\bar{Y}\right)}{\sqrt{\sum\left(X_{i}-\bar{X}\right)^{2} \sum\left(Y_{i}-\bar{Y}\right)^{2}}}, \\
\text { RMSE }=\sqrt{\frac{(X-Y)^{2}}{n}},
\end{gathered}
$$

where $X$ refers to the SPI estimates value obtained using the SPPs, $\bar{X}$ refers to the mean value of $X$ variable, $Y$ refers to the reference SPI values obtained using rain gauge measurement, and $\bar{Y}$ refers to the mean value of the Y variable, respectively. The larger the value of PCC and the lower the value of RMSE, the higher the reliability of the estimate.

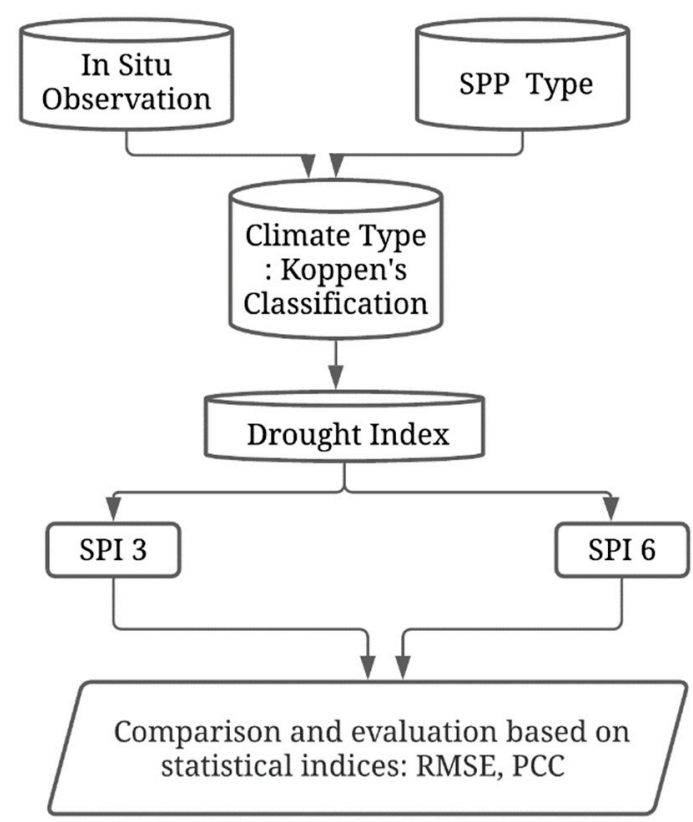

Figure 3. Flowchart of the methodology used to evaluate the suitability of SPPs in monitoring meteorological drought across various climate types.

\subsubsection{Effect of Data Record Length on the Performance of SPPs in Drought Monitoring}

To evaluate the effect of data record length on the performance of SPPs in drought monitoring, SPI values obtained from different record lengths were assessed. The studies were grouped into three categories: (a) study with a data record length of less than 10 years, (b) study having data record length between 10 to 20 years, and (c) study with a data 
record length of more than 20 years. PCC and RMSE were used as metrics to evaluate the performance of SPPs.

\subsubsection{Effect of Time Scales on the Performance of SPPs in Drought Monitoring}

To evaluate the performance of SPPs for drought monitoring under different time scales, the present study considered three different time scales: 3, 6, and 12-months timescales. These timescales were considered to represent different types of drought: meteorological and hydrological droughts [42]. A 3-months SPI compares the three-month precipitation over the defined period with the total precipitation of the same three months for all the years in the historical period. For example, SPI 3 for December of 2000 compares the total precipitation of October-November-December in the year 2000, with total precipitation in October-November-December of all the historical years considered for the analysis. The same is true for SPI 6 and 12, whereby six- and twelve-month precipitation over a defined period were compared. SPI 3 indicates the short and medium conditions. Information from SPI 6 and SPI 12 is associated with streamflow and reservoir level [15].

\section{Results}

\subsection{Overall Performance of SPPs in Drought Monitoring}

SPPs have been tested and validated against ground-based observation for drought monitoring across the globe, as shown in Tables 2-4. Infrared based SPPs offer more frequent interval and high spatial coverage than microwave-based SPPs [43]. On the other hand, microwave-based SPPs are more accurate than infrared-based SPPs, primarily as they can penetrate into clouds and better estimate the cloud's water content [44]. This is evident in Tables 2 and 3, as the microwave-based SPPs have a better drought performance than infrared-based SPPs. Interestingly, Table 4 indicates that the integrated based SPPs performed better than the infrared and microwave SPPs. The recently developed IMERG shows the best drought monitoring performance, with PCC values ranging between 0.96-0.99. The IMERG combined TMPA, CMORPH, and PERSIANN algorithms, thus allowing it to take advantage of infrared and microwave information [44]. This feature has allowed IMERG to strongly depict the intra-annual precipitation changes and the onset and extension of drought events [45]. However, the length of the IMERG data (2014-present) is too short for drought monitoring, which is the main challenge of SPPs [46].

Table 2. Infrared based SPPs performance in drought monitoring.

\begin{tabular}{|c|c|c|c|c|c|c|}
\hline \multirow{2}{*}{ Reference } & \multirow{2}{*}{ Country } & \multirow{2}{*}{ Analyzed Period } & \multirow{2}{*}{ SPP Type } & \multirow{2}{*}{ Time Scale } & \multicolumn{2}{|c|}{ SPI In Situ vs. SPI with SPP } \\
\hline & & & & & PCC & RMSE \\
\hline [23] & India & 1998-2016 & CHIRPS & SPI 3 & 0.87 & NA \\
\hline [47] & China & 1981-2016 & CHIRPS & SPI $1,3,6,12$ & $0.85-0.89$ & $0.34-0.39$ \\
\hline [48] & China & 1981-2015 & CHIRPS & SPI $1,3,6,12$ & $0.92-0.94$ & NA \\
\hline [4] & Nepal & 1981-2010 & CHIRPS & SPI 1 & 0.57 & NA \\
\hline [3] & China & 1981-2015 & CHIRPS & SPI 3,6 & $0.84-0.89$ & NA \\
\hline [49] & Tunisia & 1981-2019 & CHIRPS & SPI 12 & 0.85 & 0.443 \\
\hline [50] & Brazil & 1994-2017 & CHIRPS & SPI 6,12 & $0.85-0.94$ & $0.33-0.54$ \\
\hline [51] & China & 1983-2015 & CHIRPS & SPI 3 & $0.89-0.92$ & $0.23-0.33$ \\
\hline [52] & Chile & 1981-2015 & CHIRPS & SPI 3,6 & & $0.63-1.13$ \\
\hline [53] & China & 1983-2016 & CHIRPS & SPI $1,3,12$ & $0.84-0.89$ & $0.25-0.28$ \\
\hline [54] & Bangladesh & 2001-2016 & CHIRPS & SPI 3,6 & 0.90 & $0.43-0.44$ \\
\hline [46] & China & 2003-2017 & CHIRPS & SPI 1,3,6,12 & $0.85-0.94$ & NA \\
\hline [23] & India & 1998-2016 & PERSIANN CDR & SPI 3 & 0.88 & NA \\
\hline [27] & China & 1983-2014 & PERSIANN CDR & SPI 6 & $0.4-0.9$ & NA \\
\hline [51] & China & 1983-2015 & PERSIANN CDR & SPI 3 & $0.94-0.97$ & $0.18-2.8$ \\
\hline [50] & Brazil & 1994-2017 & PERSIANN CDR & SPI 6,12 & $0.94-0.96$ & $0.29-0.35$ \\
\hline [25] & Iran & 1983-2012 & PERSIANN CDR & SPI 3,6,12 & $0.27-0.80$ & $0.62-1.05$ \\
\hline [53] & China & 1983-2016 & PERSIANN CDR & SPI 1,3,12 & $0.95-0.96$ & $0.15-0.18$ \\
\hline [46] & China & 2003-2017 & PERSIANN CDR & SPI 1,3,6,12 & $0.85-0.95$ & NA \\
\hline [55] & Pakistan & 2000-2015 & PERSIANN CDR & SPI 1,3,12 & NA & $1.29-1.73$ \\
\hline [54] & Bangladesh & 2001-2016 & PERSIANN CDR & SPI 3,6 & $0.90-0.91$ & 0.43 \\
\hline [52] & Chile & 1983-2015 & PERSIANN CDR & SPI 3,6 & NA & $0.63-1.06$ \\
\hline [56] & Iraq & 1983-2016 & PERSIANN CDR & SPI $3,6,12$ & $0.28-0.70$ & $-0.49-0.46$ \\
\hline
\end{tabular}




\subsection{Effect of Climatic Zones on the Performance of SPPs in Drought Monitoring}

SPPs are more suitable for estimating the tropical and temperate convection rainfall pattern than the isolated convention rainfall in dry/arid/semi-arid regions, which are difficult to estimate due to hot background surface, desert aerosols, and sub cloud evaporation $[49,50,55]$. This is also evident in Figures 4 and 5, which show that the SPPs drought-monitoring performance is higher in temperate and tropical climates than in dry and continental. CHIRPS provides the finest resolution $\left(0.05^{\circ} \times 0.05^{\circ}\right)$ and long-term data series (1981-present), as compared to the other SPPs [59]. This feature makes CHIRPS suitable for various drought applications with less uncertainties and errors [48]. However, despite its good performance, CHIRPS was also reported to depend upon the location and hydroclimatic characteristics of the regions $[68,69]$. This is evident in Figure 4, where CHIRPS showed a good relationship with the reference data-based SPI, with slight variation across different climatic types. PERSIANN CDR with a fine resolution of $0.25^{\circ}$ has shown great potential for drought monitoring across the world, although it shows discrepancies in areas with dry climate, complex terrain, and sparse gauge network [27]. This is evident in its drought performance, as shown in Figure 5. The same was noted for Tropical Measurement Measuring Mission SPPs (TMPA343V7, TMPA3B42V7), where their performance was influenced by climate type.

Table 3. Microwave based SPPs performance in drought monitoring.

\begin{tabular}{lcccccc}
\hline \multirow{2}{*}{ References } & Country & Analyzed Period & SPP Type & Time Scale & \multicolumn{2}{c}{ SPI In Situ vs. SPI with SPP } \\
\cline { 5 - 7 } & & & & PCC & RMSE \\
\hline$[57]$ & Mexico & $1998-2014$ & TRMM-3B42 V7 & SPI 1,3,6,12 & $0.06-0.79$ & NA \\
{$[58]$} & China & $1998-2013$ & TRMM-3B42 V7 & SPI 3,6,12 & $0.92-0.97$ & NA \\
{$[59]$} & China & $2015-2017$ & TRMM-3B42 V7 & SPI 1,3,6,12 & $0.23-0.84$ & $0.39-0.56$ \\
{$[46]$} & China & $2003-2017$ & TRMM-3B42 V7 & SPI 1,3,6,12 & $0.64-0.84$ & NA \\
{$[55]$} & Pakistan & $2000-2015$ & TRMM-3B42 V7 & SPI 1,3,12 & NA & $1.10-1.76$ \\
{$[23]$} & India & $1998-2016$ & TRMM-3B43 V7 & SPI 3 & 0.88 & NA \\
{$[56]$} & Iraq & $1998-2017$ & TRMM-3B43 V7 & SPI 3,6,12 & $0.32-0.90$ & $0.21-0.60$ \\
{$[60]$} & China & $1998-2014$ & TRMM-3B43 V7 & SPI 3,6,12 & $0.92-0.98$ & NA \\
{$[61]$} & Malaysia & $1998-2014$ & TRMM-3B43 V7 & SPI 3,6,12 & $0.42-0.49$ & NA \\
{$[62]$} & China & $1998-2014$ & TRMM-3B43 V7 & SPI 3,12 & $0.89-0.91$ & NA \\
{$[63]$} & China & $1998-2013$ & TRMM-3B43 V7 & SPI 1,3,6,12 & $0.98-0.99$ & NA \\
{$[64]$} & Singapore & $1998-2014$ & TRMM-3B43 V7 & SPI 1,3,6,12 & $0.76-0.80$ & $0.63-0.69$ \\
{$[65]$} & Africa & $1998-2010$ & TRMM-3B43 V7 & SPI 3 & $0.51-0.82$ & NA \\
{$[66]$} & China & $1998-2016$ & TRMM-3B43 V7 & SPI 1,3,6,12 & $0.96-0.98$ & NA \\
{$[54]$} & Bangladesh & $2001-2016$ & TRMM-3B43 V7 & SPI 3,6 & 0.90 & $0.41-0.42$ \\
{$[67]$} & China & $1998-2010$ & TRMM-3B43 V7 & SPI 3 & 0.93 & NA \\
\hline
\end{tabular}

Table 4. Integrated based SPPs performance in drought monitoring.

\begin{tabular}{ccccccc}
\hline \multirow{2}{*}{ References } & Country & Analyzed Period & SPP Type & Time Scale & \multicolumn{2}{c}{ SPI In Situ vs. SPI with SPP } \\
\cline { 5 - 7 } & & & & & PCC & RMSE \\
\hline$[46]$ & China & $2003-2017$ & IMERG & SPI 1,3,6,12 & $0.96-0.99$ & NA \\
{$[45]$} & China & $2000-2017$ & IMERG & SPI 6 & $0.96-0.99$ & $0.05-0.07$ \\
{$[55]$} & Pakistan & $2000-2015$ & IMERG & SPI 1,2 12 & NA & $1.12-1.63$ \\
{$[46]$} & China & $2003-2017$ & CMORPH & SPI 1,3,6,12 & $0.92-0.98$ & NA \\
{$[59]$} & China & $2015-2017$ & CMORPH & SPI 1,3,6,12 & $0.84-0.93$ & $0.15-0.56$ \\
\hline
\end{tabular}




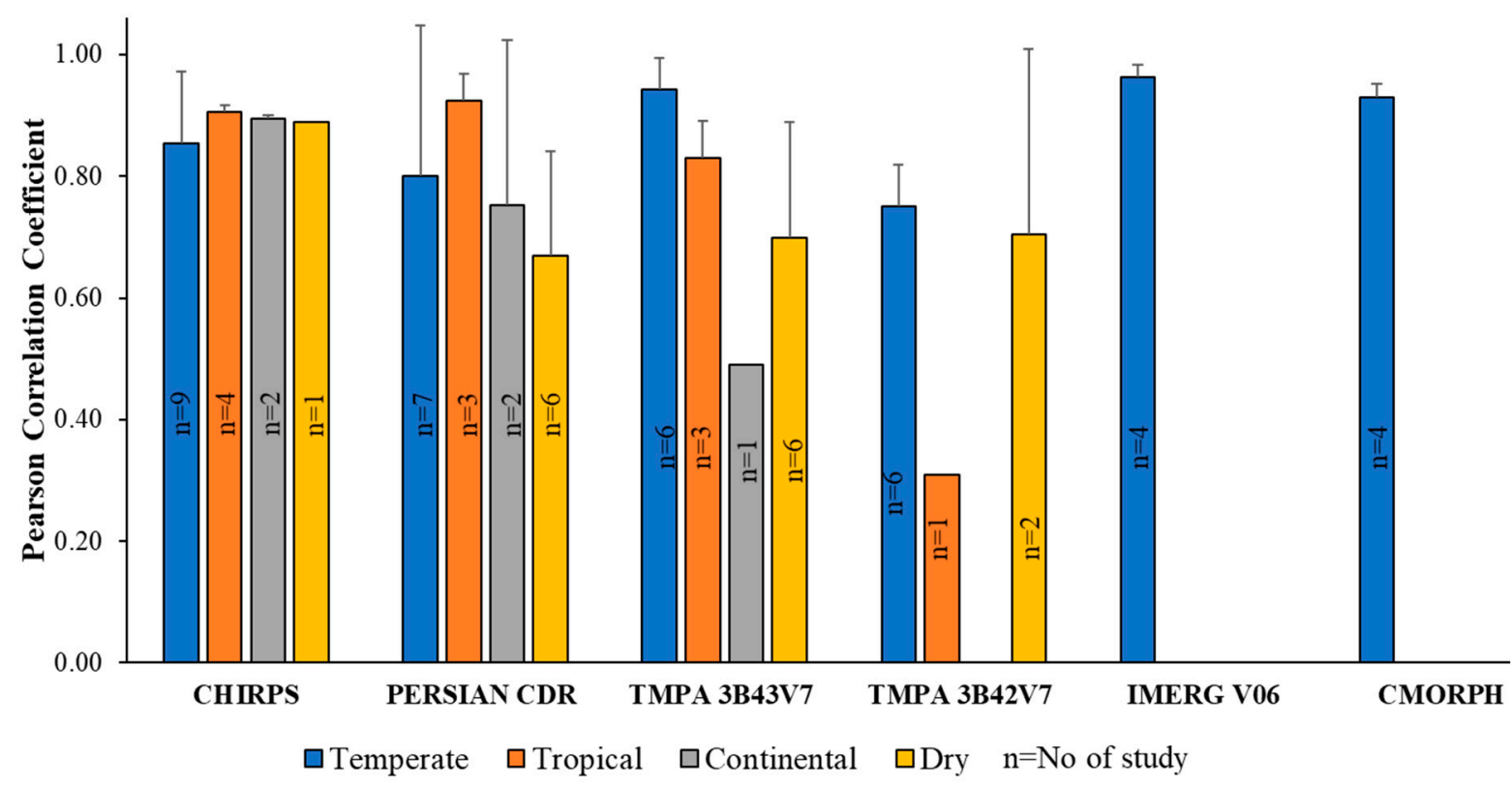

Figure 4. Performance of various SPPs for drought prediction based on 3-month SPI using PCC as a statistical index. Error bars represent the standard error in data.
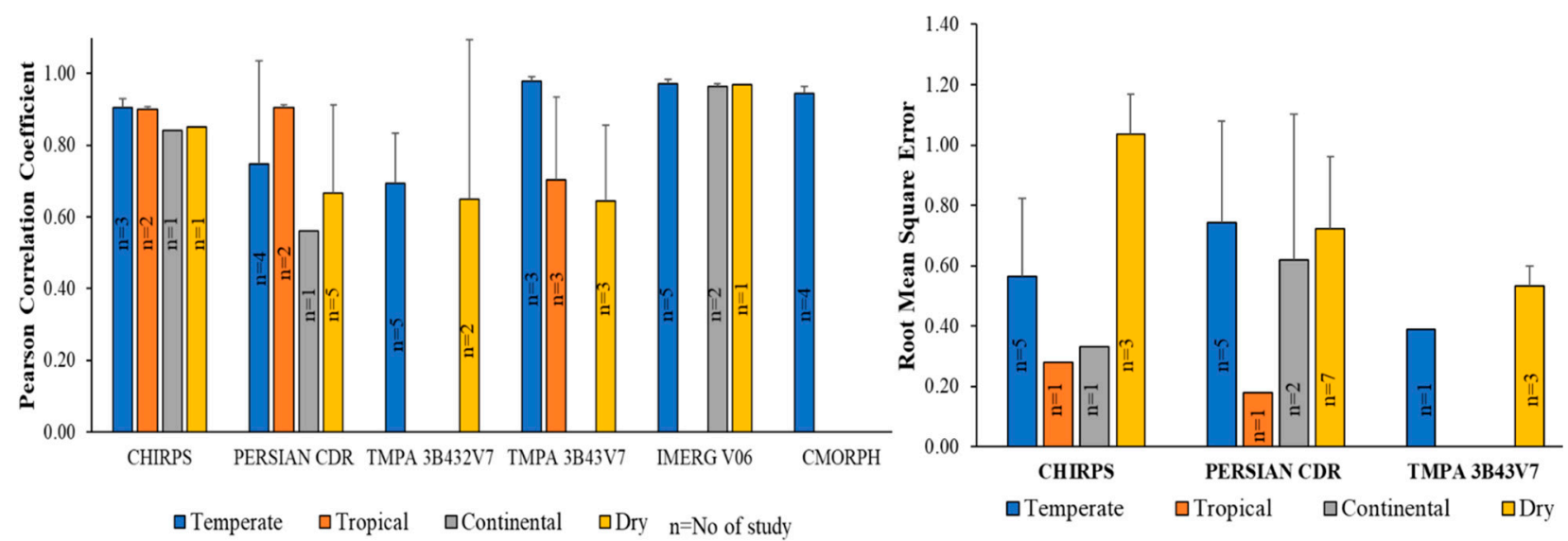

Figure 5. Performance of various SPPs for drought prediction based on 6-month SPI, using PCC and RMSE as statistical indices. Error bars represent the standard error in data.

\subsection{Effect of Data Record Length on the Performance of SPPs in Drought Monitoring}

The SPI is a widely accepted index for meteorological drought monitoring. Long-term and continuous precipitation data are necessary for the calculation of the SPI. Thus, the longer the length of the precipitation data, the more reliable the SPI value will be [70]. $\mathrm{Wu}$ et al. evaluated the effect of data record length on SPI values, and found out that there is a high correlation between the SPI value and the data record length [70]. This is also evident in Figure 6, where it was found that the data length affects the SPI estimation of SPPs. The SPPs value is higher when the data record length is more than 20 years compared to the shorter data record. The same can be seen in the case of RMSE value. A lower RMSE value was noted when the data record length is more than 20 years. This is mainly due to the dependence of precipitation trends on the data record length [71]. Additionally, it is generally accepted that a minimum record of 30 years is necessary for any hydrological and climatological study [71]. Thus, this is one of the current limitations of SPPs, as all the SPPs except CHIRPS and PERSIANN-CDR have less than 20 years of data record length. Interestingly, a study by Jin et al. suggested that the short data length of SPPs is not the primary source of error in the SPI estimation for drought monitoring; 
instead, larger uncertainties come from the climatic conditions and the complex landscape of the location [71].
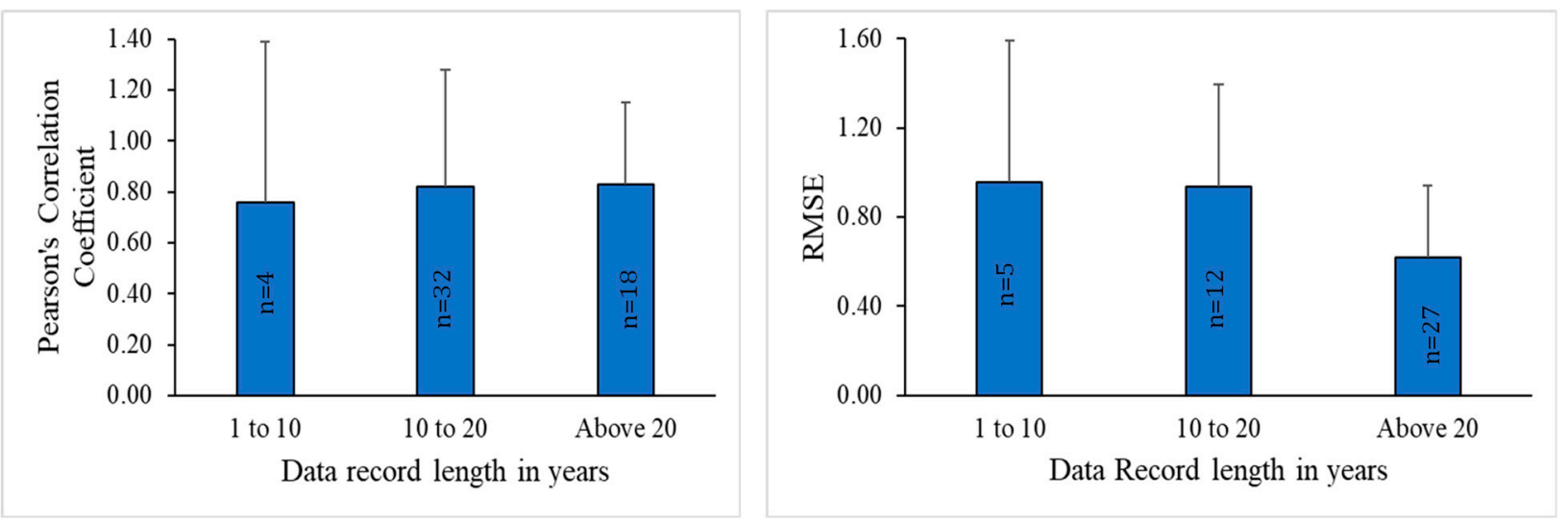

Figure 6. Effect of SPP data record length. Error bars represent the standard error in the data.

\subsection{Effect of Time Scales on the Performance of SPPs in Drought Monitoring}

To obtain the complete picture of the various drought events, SPI is recommended to be calculated at different time scales [47]. As seen from Tables 2-4, some studies focus only on a single timescale, while others focus on multiple time scales. The present study thus evaluates the performance of SPPs for drought monitoring at different time scales. Multiscale comparison through the Pearson correlation index shows no difference in the performance of SPPs across different time scales, although a slight improvement was noted as the time scale increased from 3 to 12 months for all SPPs types (Figure 7). This is further supported by the analysis of variance (ANOVA), indicating no significant difference among the different time scales $(p>0.05)$. These findings suggest that the scale has no large influence on the effect of SPPs for drought monitoring, as the best performance can be achieved at multiple time scales of interest [26].

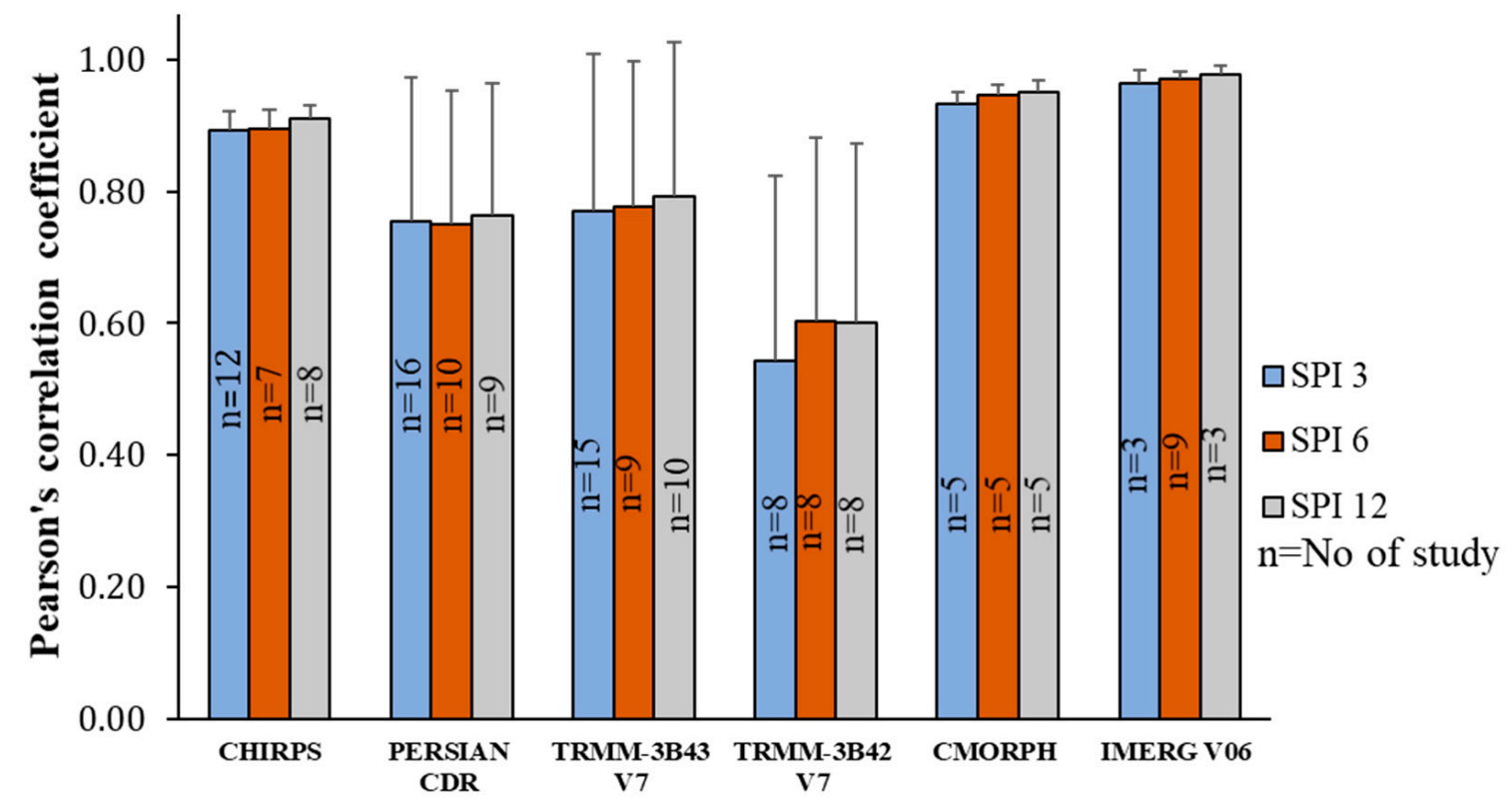

Figure 7. PCC value between SPI in situ vs. SPI with SPPs across the different time scale. Error bars represent the standard error in data. 


\section{Discussion}

Precipitation is an important variable for drought monitoring and for the calculation of many drought indices [20]. In recent years, many researchers indicated that SPPs performed well in measuring or estimating precipitation rates [72]. More importantly, these SPPs were able to represent the spatiotemporal variations of precipitation for most parts of the world with high resolution [3]. However, the accuracy of precipitation provided by these satellites is affected by many factors. One of the major disadvantages of SPP is the short data record length. At present, only PERSIANN-CDR and CHIRPS have a long-term data record of more than 30 years. Thus, many of the conducted studies could only rely on the available records. Results of the meta-analysis in this investigation revealed that several past studies have attempted to tackle the limited length of SPPs data by blending the SPPs with in situ data $[55,73,74]$. Blending SPPs with in situ data can generate continuous effective precipitation estimates with high accuracy [74]. This technique combines the advantage of the long-term in situ precipitation data with the high temporal and spatial coverage of SPPs [73]. Several techniques such as geographically weighted regression, Bayesian methods, and machine learning (ML) were used for merging different SPPs with in situ data $[74,75]$. The superiority of the blending method over the standalone SPP has been reported in various studies [76,77]. However, the same studies indicated that blending SPPs with in situ data is sensitive to the blending method, gauge density, and other factors $[55,73,74]$. For example, recent studies have highlighted the limited efficiency of machine learning and data-driven methods for drought monitoring, unless the data is pre-processed [24,78]. Pre-processing of in situ precipitation data with techniques such as wavelet transform and discrete wavelet transform has shown to improve the drought forecasting performance of machine learning techniques [78]. Thus, research in blending SPPs with in situ data can also be further investigated and improved by applying pre-processing tools such as wavelet transform.

The results of the meta-analysis also focused on investigating the impact of SPP type on its performance in drought monitoring. Results show that this can lead to a significant difference in drought performance across different climate zones. Bias-correction of SPPs was proposed as an important step before their applications in drought monitoring across various climatic conditions $[79,80]$. Several bias correction methods were attempted on SPPs, ranging from simple scaling methods to complex mapping [81,82]. The simple scaling method simply adjusts the monthly SPP value with the gauge rainfall value using a monthly correction factor [81]. This method does not adjust for the standard deviation of daily SPP values, whereas advanced methods such as quantile mapping incorporate the standard deviation of daily SPP data with respect to gauge data in bias correction [81]. The applicability of various bias correction methods was reported to vary with regions [83]. For example, in dry and warm climate regions, evaporation of hydrometeors is significant. As PMW data relies on the actual hydrometeor content, large evaporation may lead to false alarms and overestimation of PMW SPP [84]. These findings stress the need to further explore the use of SPPs and bias methods across different climate zones. Additionally, as the performance of SPPs may be influenced by other factors, more studies should be designed to block certain factors to be able to elucidate the impact of the applied bias correction method across different climatic zones.

\section{Conclusions and Way Forward}

This work reviewed the most prevalent SPPs used in drought monitoring and evaluated the factors that can potentially affect the performance of SPPs. Results of the review indicated that SPPs had their uncertainties and discrepancies along with their strengths. Through analyzing data in previous studies, it is evident that the performance of SPPs in drought monitoring is highly dependent on the climate type and length of the data record. All these findings indicate the need to further explore the use of SPP to improve its performance for drought applications. Thus, future studies should move away from 
focusing on comparing the performance of SPPs for drought monitoring and instead be directed to:

1. Identify the best climatological condition under which SPPs can be successfully used for drought monitoring.

2. Focus on merging SPPs with other satellite data of high spatial and temporal scale (e.g., soil moisture and vegetation water content) to enhance the precipitation estimation and drought monitoring process.

3. Application of various data processing methods such as wavelet packet transform (WPT), discrete wavelet transform (DWT), etc., should be attempted in SPPs to enhance the machine learning performance in blending SPPs with in situ data.

4. Bias correction such as quantile mapping etc. should be applied to SPPs before SPI estimation to improve their performance.

Author Contributions: Conceptualization, G.H., D.L, M.A.H. and M.M.M.; Data curation, G.H. and M.A.H.; Formal analysis, G.H.; Funding acquisition, M.M.M. and M.A.H.; Investigation, G.H.; Methodology, G.H.; Project administration, M.A.H. and M.M.M.; Resources, M.M.M. and M.A.H.; Supervision, D.L., M.A.H. and M.M.M.; Validation, M.A.H.; Visualization, G.H.; Writing—original draft, G.H.; Review and editing, D.L., M.A.H. and M.M.M. All authors have read and agreed to the published version of the manuscript.

Funding: This research was funded by the national water and energy center, United Arab Emirates University through the Asian University Alliance (AUA) program, grants number 31R281-AUANWEC -4- 2020, 12R023-AUA- NWEC -4- 2020, and 12R019-NWEC -6- 2020.

Data Availability Statement: The data that support the findings of this study are available on request from the corresponding author.

Conflicts of Interest: The authors declare no conflict of interest.

\section{References}

1. Trenberth, K.E.; Dai, A.; Rasmussen, R.M.; Parsons, D.B. The changing character of precipitation. Bull. Am. Meteorol. Soc. 2003, 84, 1205-1218. [CrossRef]

2. Su, F.; Hong, Y.; Lettenmaier, D.P. Evaluation of TRMM Multisatellite Precipitation Analysis (TMPA) and its utility in hydrologic prediction in the La Plata Basin. J. Hydrometeorol. 2008, 9, 622-640. [CrossRef]

3. Gao, F.; Zhang, Y.; Ren, X.; Yao, Y.; Hao, Z.; Cai, W. Evaluation of CHIRPS and its application for drought monitoring over the Haihe River Basin, China. Nat. Hazards 2018, 92, 155-172. [CrossRef]

4. Shrestha, N.K.; Qamer, F.M.; Pedreros, D.; Murthy, M.S.R.; Wahid, S.M.; Shrestha, M. Evaluating the accuracy of Climate Hazard Group (CHG) satellite rainfall estimates for precipitation based drought monitoring in Koshi basin, Nepal. J. Hydrol. Reg. Stud. 2017, 13, 138-151. [CrossRef]

5. Joyce, R.J.; Janowiak, J.E.; Arkin, P.A.; Xie, P. CMORPH: A method that produces global precipitation estimates from passive microwave and infrared data at high spatial and temporal resolution. J. Hydrometeorol. 2004, 5, 487-503. [CrossRef]

6. Funk, C.; Peterson, P.; Landsfeld, M.; Pedreros, D.; Verdin, J.; Shukla, S.; Husak, G.; Rowland, J.; Harrison, L.; Hoell, A. The climate hazards infrared precipitation with stations-A new environmental record for monitoring extremes. Sci. Data 2015, 2, 150066. [CrossRef] [PubMed]

7. Huffman, G.J.; Bolvin, D.T.; Braithwaite, D.; Hsu, K.; Joyce, R.; Xie, P.; Yoo, S.-H. NASA global precipitation measurement (GPM) integrated multi-satellite retrievals for GPM (IMERG). Algorithm Theor. Basis Doc. Version 2015, 4, 26.

8. Ashouri, H.; Hsu, K.-L.; Sorooshian, S.; Braithwaite, D.K.; Knapp, K.R.; Cecil, L.D.; Nelson, B.R.; Prat, O.P. PERSIANN-CDR: Daily precipitation climate data record from multisatellite observations for hydrological and climate studies. Bull. Am. Meteorol. Soc. 2015, 96, 69-83. [CrossRef]

9. Kummerow, C.; Barnes, W.; Kozu, T.; Shiue, J.; Simpson, J. The tropical rainfall measuring mission (TRMM) sensor package. J. Atmos. Ocean. Technol. 1998, 15, 809-817. [CrossRef]

10. Tang, G.; Ma, Y.; Long, D.; Zhong, L.; Hong, Y. Evaluation of GPM Day-1 IMERG and TMPA Version-7 legacy products over Mainland China at multiple spatiotemporal scales. J. Hydrol. 2016, 533, 152-167. [CrossRef]

11. Mahmoud, M.T.; Mohammed, S.A.; Hamouda, M.A.; Mohamed, M.M. Impact of topography and rainfall intensity on the accuracy of imerg precipitation estimates in an arid region. Remote Sens. 2021, 13, 13. [CrossRef]

12. Abdelmoneim, H.; Soliman, M.R.; Moghazy, H.M. Evaluation of TRMM 3B42V7 and CHIRPS Satellite Precipitation Products as an Input for Hydrological Model over Eastern Nile Basin. Earth Syst. Environ. 2020, 4, 685-698. [CrossRef]

13. Hong, Z.; Han, Z.; Li, X.; Long, D.; Tang, G.; Wang, J. Generation of an Improved Precipitation Dataset from Multisource Information over the Tibetan Plateau. J. Hydrometeorol. 2021, 22, 1275-1295. 
14. Hayes, M.J.; Svoboda, M.D.; Wardlow, B.D.; Anderson, M.C.; Kogan, F. Drought monitoring: Historical and current perspectives. In Remote Sensing of Drought: Innovative Monitoring Approaches; Wardlow, B.D., Anderson, M.C., Verdin, J.P., Eds.; CRC Press: Boca Raton, FL, USA, 2012; Chapter 1; pp. 1-19.

15. Sharma, A.; Goyal, M.K. Assessment of drought trend and variability in India using wavelet transform. Hydrol. Sci. J. 2020, 65, 1539-1554. [CrossRef]

16. Long, D.; Scanlon, B.R.; Longuevergne, L.; Sun, A.Y.; Fernando, D.N.; Save, H. GRACE satellite monitoring of large depletion in water storage in response to the 2011 drought in Texas. Geophys. Res. Lett. 2013, 40, 3395-3401. [CrossRef]

17. Jentsch, A.; Beierkuhnlein, C. Research frontiers in climate change: Effects of extreme meteorological events on ecosystems. Comptes Rendus Geosci. 2008, 340, 621-628. [CrossRef]

18. Dai, A. Drought under global warming: A review. Wiley Interdiscip. Rev. Clim. Chang. 2011, 2, 45-65. [CrossRef]

19. Dutta, P.; Hinge, G.; Marak, J.D.K.; Sarma, A.K. Future climate and its impact on streamflow: A case study of the Brahmaputra river basin. Model. Earth Syst. Environ. 2020, 7, 2475-2490. [CrossRef]

20. Mishra, A.K.; Singh, V.P. A review of drought concepts. J. Hydrol. 2010, 391, 202-216. [CrossRef]

21. Bonal, D.; Burban, B.; Stahl, C.; Wagner, F.; Hérault, B. The response of tropical rainforests to drought-lessons from recent research and future prospects. Ann. For. Sci. 2016, 73, 27-44. [CrossRef]

22. Yang, Y.; Guan, H.; Batelaan, O.; McVicar, T.R.; Long, D.; Piao, S.; Liang, W.; Liu, B.; Jin, Z.; Simmons, C.T. Contrasting responses of water use efficiency to drought across global terrestrial ecosystems. Sci. Rep. 2016, 6, 23284. [CrossRef] [PubMed]

23. Pandey, V.; Srivastava, P.K.; Mall, R.K.; Munoz-Arriola, F.; Han, D. Multi-satellite precipitation products for meteorological drought assessment and forecasting in Central India. Geocarto Int. 2020. [CrossRef]

24. Hinge, G.; Sharma, A. Comparison of wavelet and machine learning methods for regional drought prediction. In Proceedings of the EGU General Assembly Conference Abstracts, Vienna, Austria, 25-30 April 2021. [CrossRef]

25. Alijanian, M.; Rakhshandehroo, G.R.; Mishra, A.; Dehghani, M. Evaluation of remotely sensed precipitation estimates using PERSIANN-CDR and MSWEP for spatio-temporal drought assessment over Iran. J. Hydrol. 2019, 579, 124189. [CrossRef]

26. Luo, X.; Wu, W.; He, D.; Li, Y.; Ji, X. Hydrological simulation using TRMM and CHIRPS precipitation estimates in the lower Lancang-Mekong river basin. Chin. Geogr. Sci. 2019, 29, 13-25. [CrossRef]

27. Guo, H.; Bao, A.; Liu, T.; Chen, S.; Ndayisaba, F. Evaluation of PERSIANN-CDR for meteorological drought monitoring over China. Remote Sens. 2016, 8, 379. [CrossRef]

28. Huffman, G.J.; Bolvin, D.T.; Nelkin, E.J.; Wolff, D.B.; Adler, R.F.; Gu, G.; Hong, Y.; Bowman, K.P.; Stocker, E.F. The TRMM Multisatellite Precipitation Analysis (TMPA): Quasi-global, multiyear, combined-sensor precipitation estimates at fine scales. J. Hydrometeorol. 2007, 8, 38-55. [CrossRef]

29. Wang, F.; Yang, H.; Wang, Z.; Zhang, Z.; Li, Z. Drought evaluation with CMORPH satellite precipitation data in the Yellow River Basin by using gridded standardized precipitation evapotranspiration index. Remote Sens. 2019, 11, 485. [CrossRef]

30. Jiang, S.; Wei, L.; Ren, L.; Xu, C.-Y.; Zhong, F.; Wang, M.; Zhang, L.; Yuan, F.; Liu, Y. Utility of integrated IMERG precipitation and GLEAM potential evapotranspiration products for drought monitoring over mainland China. Atmos. Res. 2021, $247,105141$. [CrossRef]

31. Wilhite, D. Drought monitoring and early warning: Concepts, progress and future challenges. World Meteorol. Organ. WMO 2006, $1006,26$.

32. Svoboda, M.D.; Fuchs, B.A. Handbook of Drought Indicators and Indices; World Meteorological Organization: Geneva, Switzerland, 2016; ISBN 9187823241.

33. McKee, T.B.; Doesken, N.J.; Kleist, J. The relationship of drought frequency and duration to time scales. In Proceedings of the 8th Conference on Applied Climatology, Anaheim, CA, USA, 17-22 January 1993; Volume 17, pp. 179-183.

34. Hayes, M.; Svoboda, M.; Wall, N.; Widhalm, M. The Lincoln declaration on drought indices: Universal meteorological drought index recommended. Bull. Am. Meteorol. Soc. 2011, 92, 485-488. [CrossRef]

35. Hao, Z.; AghaKouchak, A.; Nakhjiri, N.; Farahmand, A. Global integrated drought monitoring and prediction system. Sci. Data 2014, 1, 140001. [CrossRef]

36. Brown, J.F.; Wardlow, B.D.; Tadesse, T.; Hayes, M.J.; Reed, B.C. The Vegetation Drought Response Index (VegDRI): A new integrated approach for monitoring drought stress in vegetation. GISci. Remote Sens. 2008, 45, 16-46. [CrossRef]

37. Anderson, M.C.; Zolin, C.A.; Sentelhas, P.C.; Hain, C.R.; Semmens, K.; Yilmaz, M.T.; Gao, F.; Otkin, J.A.; Tetrault, R. The Evaporative Stress Index as an indicator of agricultural drought in Brazil: An assessment based on crop yield impacts. Remote Sens. Environ. 2016, 174, 82-99. [CrossRef]

38. Zhang, X.; Chen, N.; Li, J.; Chen, Z.; Niyogi, D. Multi-sensor integrated framework and index for agricultural drought monitoring. Remote Sens. Environ. 2017, 188, 141-163. [CrossRef]

39. AghaKouchak, A.; Farahmand, A.; Melton, F.S.; Teixeira, J.; Anderson, M.C.; Wardlow, B.D.; Hain, C.R. Remote sensing of drought: Progress, challenges and opportunities. Rev. Geophys. 2015, 53, 452-480. [CrossRef]

40. Trenberth, K.E.; Dai, A.; Van Der Schrier, G.; Jones, P.D.; Barichivich, J.; Briffa, K.R.; Sheffield, J. Global warming and changes in drought. Nat. Clim. Chang. 2014, 4, 17-22. [CrossRef]

41. Rubel, F.; Kottek, M. Observed and projected climate shifts 1901-2100 depicted by world maps of the Köppen-Geiger climate classification. Meteorol. Z. 2010, 19, 135. [CrossRef] 
42. Edwards, D.C. Characteristics of 20th Century Drought in the United States at Multiple Time Scales; Air Force Inst of Tech., WrightPatterson AFB: Dayton, OH, USA, 1997.

43. Sorooshian, S.; AghaKouchak, A.; Arkin, P.; Eylander, J.; Foufoula-Georgiou, E.; Harmon, R.; Hendrickx, J.M.H.; Imam, B.; Kuligowski, R.; Skahill, B. Advanced concepts on remote sensing of precipitation at multiple scales. Bull. Am. Meteorol. Soc. 2011, 92, 1353-1357. [CrossRef]

44. Kummerow, C.; Hong, Y.; Olson, W.S.; Yang, S.; Adler, R.F.; McCollum, J.; Ferraro, R.; Petty, G.; Shin, D.-B.; Wilheit, T.T. The evolution of the Goddard Profiling Algorithm (GPROF) for rainfall estimation from passive microwave sensors. J. Appl. Meteorol. 2001, 40, 1801-1820. [CrossRef]

45. Wei, L.; Jiang, S.; Ren, L.; Zhang, L.; Wang, M.; Duan, Z. Preliminary Utility of the Retrospective IMERG Precipitation Product for Large-Scale Drought Monitoring over Mainland China. Remote Sens. 2020, 12, 2993. [CrossRef]

46. Xiao, S.; Xia, J.; Zou, L. Evaluation of multi-satellite precipitation products and their ability in capturing the characteristics of extreme climate events over the Yangtze River Basin, China. Water 2020, 12, 1179. [CrossRef]

47. Guo, H.; Bao, A.; Liu, T.; Ndayisaba, F.; He, D.; Kurban, A.; De Maeyer, P. Meteorological drought analysis in the Lower Mekong Basin using satellite-based long-term CHIRPS product. Sustainability 2017, 9, 901. [CrossRef]

48. Wu, W.; Li, Y.; Luo, X.; Zhang, Y.; Ji, X.; Li, X. Performance evaluation of the CHIRPS precipitation dataset and its utility in drought monitoring over Yunnan Province, China. Geomat. Nat. Hazards Risk 2019, 10, 2145-2162. [CrossRef]

49. Bouaziz, M.; Medhioub, E.; Csaplovisc, E. A machine learning model for drought tracking and forecasting using remote precipitation data and a standardized precipitation index from arid regions. J. Arid Environ. 2021, 189, 104478. [CrossRef]

50. De Brito, C.S.; da Silva, R.M.; Santos, C.A.G.; Neto, R.M.B.; Coelho, V.H.R. Monitoring meteorological drought in a semiarid region using two long-term satellite-estimated rainfall datasets: A case study of the Piranhas River basin, northeastern Brazil. Atmos. Res. 2021, 250, 105380. [CrossRef]

51. Zhong, R.; Chen, X.; Lai, C.; Wang, Z.; Lian, Y.; Yu, H.; Wu, X. Drought monitoring utility of satellite-based precipitation products across mainland China. J. Hydrol. 2019, 568, 343-359. [CrossRef]

52. Zambrano, F.; Wardlow, B.; Tadesse, T.; Lillo-Saavedra, M.; Lagos, O. Evaluating satellite-derived long-term historical precipitation datasets for drought monitoring in Chile. Atmos. Res. 2017, 186, 26-42. [CrossRef]

53. Wei, L.; Jiang, S.; Ren, L.; Yuan, F.; Zhang, L. Performance of Two Long-Term Satellite-Based and GPCC 8.0 precipitation products for drought monitoring over the Yellow River Basin in China. Sustainability 2019, 11, 4969. [CrossRef]

54. Prodhan, F.A.; Zhang, J.; Bai, Y.; Sharma, T.P.P.; Koju, U.A. Monitoring of Drought Condition and Risk in Bangladesh Combined Data From Satellite and Ground Meteorological Observations. IEEE Access 2020, 8, 93264-93282. [CrossRef]

55. Rahman, K.U.; Shang, S.; Zohaib, M. Assessment of Merged Satellite Precipitation Datasets in Monitoring Meteorological Drought over Pakistan. Remote Sens. 2021, 13, 1662. [CrossRef]

56. Suliman, A.H.A.; Awchi, T.A.; Al-Mola, M.; Shahid, S. Evaluation of remotely sensed precipitation sources for drought assessment in Semi-Arid Iraq. Atmos. Res. 2020, 242, 105007. [CrossRef]

57. De Jesús, A.; Breña-Naranjo, J.A.; Pedrozo-Acuña, A.; Alcocer Yamanaka, V.H. The use of TRMM 3B42 product for drought monitoring in Mexico. Water 2016, 8, 325. [CrossRef]

58. Jiang, S.; Ren, L.; Zhou, M.; Yong, B.; Zhang, Y.; Ma, M. Drought monitoring and reliability evaluation of the latest TMPA precipitation data in the Weihe River Basin, Northwest China. J. Arid Land 2017, 9, 256-269. [CrossRef]

59. Zhu, Q.; Luo, Y.; Zhou, D.; Xu, Y.-P.; Wang, G.; Gao, H. Drought monitoring utility using satellite-based precipitation products over the Xiang River Basin in China. Remote Sens. 2019, 11, 1483. [CrossRef]

60. Tao, H.; Fischer, T.; Zeng, Y.; Fraedrich, K. Evaluation of TRMM 3B43 precipitation data for drought monitoring in Jiangsu Province, China. Water 2016, 8, 221. [CrossRef]

61. Tan, M.L.; Tan, K.C.; Chua, V.P.; Chan, N.W. Evaluation of TRMM product for monitoring drought in the Kelantan River Basin, Malaysia. Water 2017, 9, 57. [CrossRef]

62. Zhao, Q.; Chen, Q.; Jiao, M.; Wu, P.; Gao, X.; Ma, M.; Hong, Y. The temporal-spatial characteristics of drought in the Loess Plateau using the remote-sensed TRMM precipitation data from 1998 to 2014. Remote Sens. 2018, 10, 838. [CrossRef]

63. Yan, G.; Liu, Y.; Chen, X. Evaluating satellite-based precipitation products in monitoring drought events in southwest China. Int. J. Remote Sens. 2018, 39, 3186-3214. [CrossRef]

64. Tan, M.L.; Chua, V.P.; Tan, K.C.; Brindha, K. Evaluation of TMPA 3B43 and NCEP-CFSR precipitation products in drought monitoring over Singapore. Int. J. Remote Sens. 2018, 39, 2089-2104. [CrossRef]

65. Naumann, G.; Barbosa, P.; Carrao, H.; Singleton, A.; Vogt, J. Monitoring drought conditions and their uncertainties in Africa using TRMM data. J. Appl. Meteorol. Climatol. 2012, 51, 1867-1874. [CrossRef]

66. Chen, S.; Zhang, L.; Zhang, Y.; Guo, M.; Liu, X. Evaluation of Tropical Rainfall Measuring Mission (TRMM) satellite precipitation products for drought monitoring over the middle and lower reaches of the Yangtze River Basin, China. J. Geogr. Sci. 2020, 30, 53-67. [CrossRef]

67. Yan, N.; Wu, B.; Chang, S.; Bao, X. Evaluation of TRMM Precipitation Product for Meteorological Drought Monitoring in Hai Basin. IOP Conf. Ser. Earth Environ. Sci. 2014, 17, 12093. [CrossRef]

68. Geleta, C.D.; Deressa, T.A. Evaluation of Climate Hazards Group InfraRed Precipitation Station (CHIRPS) satellite-based rainfall estimates over Finchaa and Neshe Watersheds, Ethiopia. Eng. Rep. 2021, 3, e12338. 
69. Gebremicael, T.G.; Mohamed, Y.A.; van der Zaag, P.; Berhe, A.G.; Haile, G.G.; Hagos, E.Y.; Hagos, M.K. Comparison and validation of eight satellite rainfall products over the rugged topography of Tekeze-Atbara Basin at different spatial and temporal scales. Hydrol. Earth Syst. Sci. Discuss. 2017. [CrossRef]

70. Wu, H.; Hayes, M.J.; Wilhite, D.A.; Svoboda, M.D. The effect of the length of record on the standardized precipitation index calculation. Int. J. Climatol. J. R. Meteorol. Soc. 2005, 25, 505-520. [CrossRef]

71. Lu, J.; Jia, L.; Menenti, M.; Yan, Y.; Zheng, C.; Zhou, J. Performance of the standardized precipitation index based on the TMPA and CMORPH precipitation products for drought monitoring in China. IEEE J. Sel. Top. Appl. Earth Obs. Remote Sens. 2018, 11, 1387-1396. [CrossRef]

72. Mohammed, S.A.; Hamouda, M.A.; Mahmoud, M.T.; Mohamed, M.M. Performance of GPM-IMERG precipitation products under diverse topographical features and multiple-intensity rainfall in an arid region. Hydrol. Earth Syst. Sci. Discuss. 2020. [CrossRef]

73. Rahman, K.U.; Shang, S.; Shahid, M.; Li, J. Developing an ensemble precipitation algorithm from satellite products and its topographical and seasonal evaluations over Pakistan. Remote Sens. 2018, 10, 1835. [CrossRef]

74. Bai, X.; Wu, X.; Wang, P. Blending long-term satellite-based precipitation data with gauge observations for drought monitoring: Considering effects of different gauge densities. J. Hydrol. 2019, 577, 124007. [CrossRef]

75. Lin, P.; Pan, M.; Allen, G.H.; de Frasson, R.P.; Zeng, Z.; Yamazaki, D.; Wood, E.F. Global estimates of reach-level bankfull river width leveraging big data geospatial analysis. Geophys. Res. Lett. 2020, 47, e2019GL086405. [CrossRef]

76. Lin, A.; Wang, X.L. An algorithm for blending multiple satellite precipitation estimates with in situ precipitation measurements in Canada. J. Geophys. Res. Atmos. 2011, 116. [CrossRef]

77. Jin, B.; Wu, Y.; Miao, B.; Wang, X.L.; Guo, P. Bayesian spatiotemporal modeling for blending in situ observations with satellite precipitation estimates. J. Geophys. Res. Atmos. 2014, 119, 1806-1819. [CrossRef]

78. Das, P.; Naganna, S.R.; Deka, P.C.; Pushparaj, J. Hybrid wavelet packet machine learning approaches for drought modeling. Environ. Earth Sci. 2020, 79, 221. [CrossRef]

79. Saber, M.; Yilmaz, K.K. Evaluation and bias correction of satellite-based rainfall estimates for modelling flash floods over the Mediterranean region: Application to Karpuz River Basin, Turkey. Water 2018, 10, 657. [CrossRef]

80. Habib, E.; Haile, A.T.; Sazib, N.; Zhang, Y.; Rientjes, T. Effect of bias correction of satellite-rainfall estimates on runoff simulations at the source of the Upper Blue Nile. Remote Sens. 2014, 6, 6688-6708. [CrossRef]

81. Katiraie-Boroujerdy, P.-S.; Rahnamay Naeini, M.; Akbari Asanjan, A.; Chavoshian, A.; Hsu, K.; Sorooshian, S. Bias Correction of Satellite-Based Precipitation Estimations Using Quantile Mapping Approach in Different Climate Regions of Iran. Remote Sens. 2020, 12, 2102. [CrossRef]

82. Sohn, B.J.; Han, H.-J.; Seo, E.-K. Validation of satellite-based high-resolution rainfall products over the Korean Peninsula using data from a dense rain gauge network. J. Appl. Meteorol. Climatol. 2010, 49, 701-714. [CrossRef]

83. Maggioni, V.; Massari, C. On the performance of satellite precipitation products in riverine flood modeling: A review. J. Hydrol. 2018, 558, 214-224. [CrossRef]

84. Serrat-Capdevila, A.; Valdes, J.B.; Stakhiv, E.Z. Water management applications for satellite precipitation products: Synthesis and recommendations. JAWRA J. Am. Water Resour. Assoc. 2014, 50, 509-525. [CrossRef] 